\title{
ASPEK KEBAHASAAN DALAM ANTOLOGI PUISI HULU SUNGAI TENGAH DALAM PANTUN DAN PUISI
}

\author{
Johan Arifin, Fajrika Ramadania, dan Riduan Saberan \\ Pendidikan Bahasa dan Sastra Indonesia \\ STKIP PGRI Banjarmasin \\ Jalan Sultan Adam, Komplek H. Iyus, No. 18 RT.23 Banjarmasin, \\ Kalimantan Selatan. Kode pos 70121
}

\begin{abstract}
ABSTRAK
Penelitian ini berkenaan dengan aspek kebahasaan yang ada dalam antologi puisi Hulu Sungai Tengah dalam Pantun dan Puisi terbitan Scripta Cendikia. Tujuan penelitian ini adalah untuk mengungkapkan serta mendeskripsikan aspek kebahasaan yang terdapat dalam antologi puisi Hulu Sungai Tengah dalam Pantun dan Puisi terbitan Scripta.

Penelitian ini menggunakan pendekatan antropologis dilaksanakan dengan metode deskriptif analisis dan menggali data yang ditempuh dengan menggunakan teknik observasi teks dan teknik dokumentasi. Setelah data terkumpul kemudian dianalisis dengan teknik deskriptif interpreatatif, yaitu peneliti memaparkan data secara keseluruhan terlebih dahulu, setelah data terkumpul dan terjaring peneliti menginterprestasikan untuk menganalisis data yang dilakukan melalui tahapan : (1) Pengorganisasian data,(2) interpretasi,(3) evaluasi.

Berdasarkan hasil penelitian diperoleh simpulan sebagai berikut Aspek kebahasaan yang meliputi: a) fonologis dominan dengan bunyi vokal a ,e, i, dan $\mathrm{u}, \mathrm{b}$ ) leksikal terdapat 321 kata yang dominan mengandung bunyi vokal a,e,i, dan u, juga banyak terdapat pengulangan kata, c) gramatikal, disusun secara linier dan tidak ada penyimpangan struktur.
\end{abstract}

Kata Kunci: antropologi sasta, puisi, pantun

\section{PENDAHULUAN}

Sastra adalah suatu bentuk dan hasil pekerjaan seni kreatif yang obyeknya adalah manusia dan kehidupannya dengan menggunakan bahasa sebagai mediumnya. Sebagai seni kreatif yang menggunakan manusia dan segala macam segi kehidupannya maka ia tidak saja merupakan suatu media untuk menyampaikan ide, teori, atau sistem berpikir, tetapi juga merupakan media untuk menampung ide, teori, atau sistem berpikir manusia. Sebagai karya kreatif, sastra harus mampu melahirkan suatu kreasi yang indah dan berusaha menyalurkan kebutuhan keindahan manusia. Disamping itu pula sastra harus mampu menjadi wadah penyampaian ide-ide yang dipikirkan dan dirasakan oleh sastrawan tentang kehidupan umar manusia.

Bahasa dan sastra merupakan dua unsur yang tak terpisahkan dalam kebudayaan manusia. Keduanya saling memberi dan menerima. "Sastra, suatu komunikasi seni yang hidup bersama bahasa. Tanpa bahasa, sastra tak mungkin ada. Melalui bahasa, ia dapat mewujudkan dirinya berupa sastra lisan maupun tulisan”. Disatu pihak, sastra merupakan salah satu bentuk pengungkapan bahasa, dilain pihak bahasa akan lebih terasa hidup berkat sentuhan estetis unsur-unsur sastra . 
Sastra dan pemahaman terhadapnya bukan saja memberikan kesempatan kepada kita untuk menikmatinya dalam beberapa jam, menghindarkan dari kerumitan hidup, tetapi juga memberikan kepada kita pengalaman hidup dalam pengertian yang sebenar-benarnya. Karya sastra memungkinkan kita turut berpartisifasi secara seolah-olah mengalami sendiri apa-apa yang dialami orang lain dalam dunia fiksi.

Karya sastra yang dijadikan objek penelitian adalah karya sastra berbentuk puisi. Karena puisi memiliki bahasa yang indah dan setiap katanya mempunyai arti tersendiri, sehingga peneliti tertarik untuk meneliti beberapa puisi dengan menggunakan kajian antropologis.

Pemahaman puisi tidak dapat dilepaskan dari latar belakang kemasyarakatan dan budayanya. Karya sastra itu mencerminkan masyarakat dan secara tidak terhindarkan dipersiapkan oleh keadaan masyarakat dan kekuatan-kekuatan pada zamannya). Hal ini mengingat bahwa sastrawan itu adalah anggota masyarakat, maka ia tak dapat lepas dari pengaruh sosial-budaya masyarakat. Latar sosial-budaya itu terwujud dalam tokoh-tokoh yang dikemukakan, sistem masyarakat, adat-istiadat, pandangan masyarakat, kesenian, dan bendabenda kebudayaan yang terungkap dalam karya sastra ( Pradopo, 2010:254)

Puisi bukan memberikan petunjuk atau informasi, melainkan memberikan gambaran yang dapat mempertajam kesadaran orang dan dapat membangkitkan tanggapan orang atas apa yang dibacanya ( puisi). Karena itu, untuk memahami karya sastra ( puisi) haruslah karya sastra itu dianalisis. Dengan dianalisis secara menyeluruh, maka makna pada sastra dapat ditangkap dan dipahami.

Salah satu kumpulan puisi yang sangat menarik untuk diteliti mengenai lingkungan kebudayaan Hulu Sungai ( Banjar) yaitu dalam antologi puisi Banua Hulu Sungai Tengah dalam Pantun dan Puisi. Puisi ditulis dengan bahasa Indonesia dan di tulis oleh penyairpenyair yang berasal dari kalangan etnis Banjar yang lahir, tinggal, atau pernah tinggal di Banjar.

Berdasarkan latar belakang di atas, Pemilihan antologi tersebut sebagai objek analisis dalam penalitian ini didasarkan pada alasan bahwa puisi-puisi yang terdapat dalam Antologi Puisi Banua Hulu Sungai Tengah dalam Pantun dan Puisi tersebut ditulis oleh penyair-penyair Banua Hulu Sungai ( Banjar) dan penelitian ini merupakan bentuk rasa cinta dan penghargaan terhadap budaya Banjar khususnya Hulu Sungai. 


\section{METODE}

Pendekatan yang digunakan dalam penelitian ini adalah pendekatan antropologis. Antropologis adalah ilmu pengetahuan mengenai manusia dalam masyarakat. Oleh karena itulah, antropologi dibedakan menjadi antropologi fisik dan antropologi kebudayaan, yang sekarang berkembang menjadi studi kultural. Dalam kaitannya dengan sastra , antropologi dibedakan menjadi dua bidang, yaitu antropologi dengan objek verbal dan nonverbal. Pendekatan antropologi lebih banyak berkaitan dengan verbal ( Ratna, $2011: 63$ ).

Metode penelitian yang digunakan dalam penelitian ini adalah metode diskriptif analisis, yaitu metode yang dilakukan dengan cara mendeskripsikan fakta-fakta kemudian disusul dengan analisis. Secara etimologis deskripsi dan analisis berarti menguraikan. Meskipun demikian, analisis yang berasal dari bahasa Yunani, analyein ( 'ana' = atas, ' lyein' = lepas, urai ), telah diberikan arti tambahan, tidak semata-mata menguraikan melainkan juga memberikan pemahaman dan penjelasan secukupnya.

Sumber data dalam penelitian ini adalah keseluruhan puisi yang terdapat di dalam antologi Puisi "Hulu Sungai Tengah dalam Pantun dan Puisi" terbitan Scripta Cendikia. Data penelitian ini berupa kutipan kata-kata atau kalimat puisi yang berkaitan dengan kebudayaan dalam antologi puisi Hulu Sungai Tengah dalam Pantun dan Puisi.

Teknik yang digunakan untuk pengumpulan data adalah teknik rekapitulasi dan dokomentasi.

Langkah-langkah kerja pengumpulan data dalam penelitian ini, yaitu:

1) Membaca keseluruhan puisi yang akan diteliti dan memahami isi puisi tersebut

2) Memilih dan menentukan data sesuai dengan masalah yang akan diteliti..

3) Mendokomentasikan data yang telah ditentukan.

Setelah data terkumpul kegiatan berikutnya adalah melakukan analisis data dengan metode deskripsi yaitu metode yang digunakan untuk memaparkan kata yang dianalisis.

Semua data analisis melalui tahap-tahap sebagai berikut:

1) Penguntaian dan pengorganisasian data

2) Interpretasi

3) Evaluasi

\section{HASIL DAN PEMBAHASAN}

\section{Barabai, Kotaku}

Penuh sesak makhluk ciptaannya

Bangunan nan kokoh berjejer

Semua orang sibuk

Hilir mudik, ke sana ke sini

Seolah tak henti-hentinya 
Makhluk ciptaannya menggunduli bumi

\author{
Deru suara kendaraan \\ Sesakkan telinga asap-asap mengepul \\ Menyapu debu aspal \\ Yang mengiring \\ Di sana Dwi Warna \\ Hijau membentang luas penuh \\ Dengan pesepak bola tiap sore \\ Hingga petang \\ Muda-mudi disekelilingnya \\ Bertengger bagaikan burung \\ Dengan nyanyian \\ Tawa canda mereka
}

Seakan tak pernah peduli

Dengan keadaan kota ini...

Melalui puisi yang berjudul “ Barabai, Kotaku” karya Waliyudin ini dapat diketahui keadaan Kota Barabai yang penuh sesak dengan masyarakat serta barbagai bangunan yang berjejer mengelilinginya dan berbagai aktivitasnya masyarakat ada yang sibuk menggunduli bumi. Pada bait berikutnya, penyair mengatakan terdengar suara kendaraan yang sangat mengganggu pendengaran “ deru suara kendaraan/sesakkan telinga/ asap-asap mengepul/ menyapu debu aspal/ yang mengiring”. Pengarang juga menggambarkan di Dwi Warna dengan keindahannya dan banyak muda-mudi yang melakukan aktivitasnya seperti bermain bola serta banyak lagi yang menyaksikan disekelilingnya, sehingga tidak ada yang peduli dengan keadaan kota Barabai.

\title{
Aspek Kebahasaan dalam Puisi “ Barabai, Kotaku” karya Waliyudin
}

\section{Unsur Fonologis puisi “ Barabai, Kotaku” karya Waliyudin}

Berkaitan dengan unsur fonologis, pada puisi” Barabai, Kotaku” karya Waliyudin setiap akhir larik terdapat beberapa bunyi vokal dan konsunan yang berbeda-beda. Pada bait pertama, diakhir larik pertama terdapat bunyi vokal a pada kata ciptaanNya, larik kedua terdapat bunyi konsunan $r$ pada kata berjejer, larik ketiga terdapat bunyi konsunan $k$ pada kata sibuk, larik keempat terdapat bunyi vokal $i$ pada kata kemari, larik kelima terdapat bunyi vokal a pada kata hentihentinya, dan larik keenam terdapat bunyi vokal $i$ disetiap akhir lariknya pada kata bumi. Pada bait kedua, pada larik pertama diakhir larik terdapat bunyi konsunan $n$ pada kata kendaraan, larik kedua terdapat bunyi vokal $a$ pada kata telinga, larik ketiga dan keempat terdapat bunyi konsunan $l$ pada kata mengepul dan aspal, dan larik kelima terdapat bunyi konsunan $g$ pada kata mengiring. Pada bait ketiga, disetiap akhir lariknya, pada larik pertama terdapat bunyi vokal a pada kata Dwi Warna, larik kedua terdapat bunyi konsunan $h$ pada kata penuh, larik ketiga terdapat bunyi vokal $e$ pada 
kata sore, larik keempat terdapat bunyi konsunan $g$ pada kata petang, larik kelima terdapat bunyi vokal $a$ pada kata disekelilingnya, larik keenam terdapat bunyi konsunan $g$ pada kata burung, larik ketujuh terdapat bunyi konsunan $n$ pada kata nyanyian, dan larik kedelapan terdapat bunyi vokal $a$ pada kata mereka. Dan bait keempat, dilarik pertama dan kedua memiliki persamaan bunyi vokal $i$ pada kata perduli dan kota ini. Secara keselurahan puisi tersebut bunyi vokal dan konsunan yang berbeda-beda , tampaknya terkait dengan apa yang ingin dikemukakan penyair. Secara keseluruhan puisi tersebut berbicara mengenai keadaan kota Barabai yang penuh dengan kesibukan masyarakat disekitarnya yang tidak peduli dengan lingkungan sekitarnya.

\section{Unsur Leksikal dalam Puisi”’ Barabai, Kotaku” karya Waliyudin}

Sesuai dengan suasana serta pesan yang ingin disampaikan, unsur leksikal pada puisi tersebut sangat dominan dengan kata yang mengandung bunyi vokal $a$, dan $e$. beberapa kata yang mengandung bunyi vokal $a$, dapat disebutkan misalnya makhluk, bangunan, asapasap,aspal,disana, bagaikan, tawa, canda, nyanyian. Beberapa kata yang mengandung bunyi vokal $e$, dapat disebutkan misalnya penuh, sesak, berjejer, semua, kemari, seolah, henti-hentinya, deru, membentang, pesepak, petang, bertengger, seakan, dan keadaan. Diantara beberapa kata tersebut ada yang mengandung bunyi vokal $a$ dan $e$. Bahkan ada juga kata yang diulang.

\section{Unsur Gramatikal dalam Puisi” Barabai, Kotaku” karya Waliyudin}

Bekenaan dengan unsur gramatikal, puisi tersebut ditulis larik demi larik. antara larik satu dengan larik berikutnya disusun secara linier. Ada juga larik yang ditulis tidak berdiri sendiri, melainkan merupakan satu kesatuan. Misalnya pada bait pertama, pada larik ketiga dan keempat, “ semua orang sibuk/ hilir mudik, kesana kemari”, kedua larik ini nampaknya satu kesatuan. Begitu pula pada bait kedua pada larik pertama dan kedua, " deru suara kendaraan/ sesakkan telinga", dan larik keempat dan kelima, "menyapu debu aspal/ yang mengiring". Tampaknya juga merupakan satu kesatuan. Pada bait ketiga, Nampaknya juga terdapat satu kesatuan yaitu pada larik ketiga dan keempat, “ dengan pesepak bola tiap sore/hingga petang. Juga larik keenam dan ketujuh, "bertengger bagaikan burung/dengan nyanyian”. Tidak ada penyimpangan. Walaupun tertulis kalimat dengan keadaan kota ini ..., diakhir kalimat tidak ada tanda titik-titik., tetapi penulisan seperti itu bukan suatu penyimpanga. Pernyataan seperti itu mencerminkan majas erotisis, yaitu majas yang berupa pertanyaan retoris dengan tujuan untuk mencapai efek yang lebih mendalam dan sama sekali tidak menuntut suatu jawaban” ( Tarigan,1985a: 238, dalam Effendy Tarsyad, 2011: 28). 


\section{Puisi “ Banjir’ karya Sri Rahayu}

\section{Banjir}

Musim hujan tiba

Barabai banjir

Menuangkan derita bersama

Mencari celah-celah kehidupan

Menghentikan detak jantung orang Barabai

Yang menginginkan rumah-rumah kehidupannya

Tangan dan kaki menembus getir disukma

Ingin bergarak tapi diam

Mulut terdiam menjadi saksi kebisuan kota Barabai

Bencana, segeralah berhenti,

Membebaskan semuanya

Menjadi orang yang ingin hidup bersama keluarga

Puisi "Banjir" karya Sri Rahayu ini berisi tentang keadaan kota Barabai pada musim hujan. Banjir memang langganan kota Barabai setiap tahunnya pada musim penghujan, Ketika hujan maka kota akan banjir dan masyarakat mengalami derita yang sama. Masyarakat mencari tempat agar bisa tinggal, sehingga kota Barabai tak berpenghuni.

Semua menginginkan rumah tempat tinggalnya, namun tidak bisa berbuat apa-apa karenanya. Bagaimana caranya agar tidak terjadi banjir lagi, agar keluarga bisa hidup dengan tenang.

\section{Aspek Kebahasaan dalam Puisi “ Banjir” karya Sri Rahayu \\ Unsur Fonologis dalam Puisi “ Banjir” karya Sri Rahayu}

Berkaitan dengan unsur fonologis, pada puisi "Banjir" karya Sri Rahayu, setiap akhir larik terdapat bunyi vokal maupun konsunan yang berbeda-beda. Pada bait pertama, di akhir larik pertama terdapat bunyi vokal $a$ pada kata tiba, larik kedua terdapat bunyi konsonan $r$ pada kata banjir, larik ketiga terdapat bunyi vokal a pada kata bersama, larik keempat terdapat bunyi konsonan $n$ pada kata kehidupan, dan larik kelima terdapat bunyi vokal $i$ pada kata Barabai. Pada bait kedua, dilarik pertama, kedua, dan keenam terdapat persamaan bunyi vokal $a$ pada akhir lariknya pada kata kehidupannya, di sukma, dan semuanya. Pada larik ketiga terdapat bunyi konsonan $m$ pada kata diam, larik keempat dan kelima terdapat persamaan bunyi vokal $i$ pada kata Barabai dan berhenti. Dan pada baris selanjutnya terdapat bunyi vokal a pada kata keluarga.

\section{Unsur Leksikal dalam Puisi “ Banjir” karya Sri Rahayu}

Sesuai dengan suasana serta pesan yang ingin disampaikan, unsur leksikal pada puisi tersebut dominan dengan kata yang mengandung bunyi vokal $i$. Beberapa kata yang mengandung bunyi vokal $i$ dapat disebutkan misalnya musim, Barabai, banjir, derita, mencari, penghidupan, 
ingin, tapi, getir, saksi, berhenti, dan menjadi. Bahkan beberapa kata tersebut baik dalam sebuah kata ada yang diulang.

\section{Unsur Gramatikal dalam Puisi “ Banjir” karya Sri Rahayu}

Berkenaan dengan unsur gramatikal, puisi tersebut ditulis larik demi larik. Antara larik yang satu dengan larik berikutnya disusun secara linier. Tidak ada enjambemen pada puisi tersebut. tidak ada penyimpangan struktur pada puisi tersebut walapun ada tanda koma pada

“ bencana, segeralah berhenti," pada puisi kadang tanda itu dibenarkan dan itu bukanlah suatu penyimpangan.

\section{Puisi “ Murakata Bumiku” karya Dwi Febriani}

\section{Murakata Bumiku}

Inilah bumiku...

Harum tanahnya masih sama

Ingin kucium dan ku bawa dalam pangkuan jiwa

Seperti anak mungil yang lucu

Inilah bumiku....

Jernih sungai benawa mengalir deras

Dalam terjangan anak-anak telajang dada

Bersenda gurau melawan arusnya

Inilah bumiku...

Hutan menjulang menembus awan

Lebatnya bagai sarang tawon

Menampung air agar tidak banjir

Inilah bumiku...

Setiap malam lantunan syair-syair habsy

Memuja rasul

Menerangi kota dengan Sembilan puluh Sembilan

nama Tuhan

Semoga bumiku diberkati-Nya

Puisi "murakata bumiku" karya Dwi febriani tampaknya lebih memberikan gambaran mengenai tempat tinggal penyair seperti yang di ungkapkannya “ inilah bumiku.../harum tanahnya masih sama”. Kemudian dilanjutkan dengan pernyataan "ingin ku cium dan ku bawa dalam pangkuan jiwa”. Penyair membandingkan buminya "seperti bayi mungil yang lucu”. Bait kedua, penyair kembali menggambarkan suasana sekitar tempat tinggalnya seperti yang diungkapkannya “ inilah bumiku/ jernih sungai benawa deras "penyair juga memberikan gambaran tentang apa yang disaksikannya "dalam terjangan anak-anak telanjang dada/bersenda gurau melawan arus". 
Bait ketiga, penyair kembali menyatakan “inilah bumiku..”, kemudian sehubungan fenomena yang di saksikan penyair di tempat tinggalnya, Seperti adanya " hutan yang sangat lebat, sehingga terasa sejuk yang akan menampumg air agar tidak banjir”. Selanjutnya, bagaimana gambaran penyair mengenai bumi tempat tinggalnya pada malam hari, hal itu dapat diketahui melalui bait keempat penyair menggambarkan "setiap malam lantunan syair-syair habsy /memuja Rasul/menerangi kota dengan Sembilan puluh Sembilan nama Tuhan”. Dilarik terakhir penyair mengungkapkan harapan akan bumi tempat tinggalnya "semoga bumiku diberkati".

\section{Aspek Kebahasaan dalam Puisi “ Bumi Murakata” karya Dwi Febriani}

\section{Unsur Fonologis dalam Puisi “ Bumi murakata” karya Dwi Febriani}

Berkaitan dengan unsur fonologis, puisi "bumi murakata" dominan dengan bunyi vokal $a$ dan $u$ dua unsur yang terasa berat dan rendah tampaknya terkait dengan apa yang ingin dikemukakan pada puisi tersebut, terutama mengenai gambaran lingkungan alam sekitar dengan berbagai keindahannya.

\section{Unsur Leksikal dalam Puisi “ Bumi Murakata” karya Dwi Febriani}

Unsur leksikal dalam puisi “ Bumi Murakata” karya Dwi Febriani sesuai dengan suasana dan peran yang ingin disampaikan puisi "Bumi Murakata" dominan mengandung bunyi vokal $a$ dapat disebutkan misalnya tanahnya, sama, ku bawa, dalam, jiwa, anak, awan, lebatnya, sarang, agar, malam, nama, semoga, dan diberkati-Nya.Beberapa kata yang mengandung bunyi vokal $u$ dapat disebutkan misalnya bumiku, kucium, pangkuan, mungil, lucu, dan puluh. Diantara beberapa kata tersebut ada yang mengandung bunyi vokal $a$ dan $u$ dan ada juga dalam bentuk kata maupun frasa kata yang mengandung bunyi vokal $a$ dan $u$ di ulang.

\section{Unsur Gramatikal dalam puisi “Bumi Murakata” karya Dwi Febriani}

Berkenaan dengan unsur gramatikal, puisi tersebut ditulis larik demi larik. Antara larik yang satu dengan yang laindi susun secara linier. Bahkan setiap awal bait disusun secara paralel dengan dimulai pada larik yang sama seperti “inilah bumiku...” penyusunan larik secara paralel itu selain untuk mendapatkan nilai estctis juga untuk menekankan pesan pada puisi tersebut. penyair ingin menekankan mengenai Bumi Murakata, pertama gambaran kesejukan alamnya, kedua keindahan lingkungnnya, ketiga keasrian hutannya dan keempat religiusnya begitu pula kata demi kata disusun secara gramatika, adapula terdapatlarik terutama pada kalimat "setiap malam lantunan syair-syair habsy /memuja Rasul" ditulis tidak berdiri sendiri, melainkan satu kesatuan, juga pada larik berikutnya "menerangi kota dengan Sembilan puluh Sembilan nama tuhan" tampaknya juga 
merupakan satu kesatuan . Walaupun ada tertulis kalimat seperti "inilah bumiku..."di akhir kalimat tidak ada tanda titik-titik, tetapi penulisan seperti hanya menambah nilai estetis.

\title{
Puisi “ Tak Sempat Bersyukur” karya Erfan Heri \\ Tak Sempat Bersyukur
}

\begin{abstract}
Lautan api
Dimusim Kemarau

Bagai Tsunami

Menggulung

Melahap

Setiap atap - atap

Memecah langkah

Hura-hara

Kiamat sugra

Seketika

Rumah kita

Tiada

Seketika

Aku tersungkur

Sadar

Selama ini

Tak sempat bersyukur

Melalui puisi diatas, dapat di ketahui sesuai dengan judulnya " Tak Sempat Bersyukur" tampaknya lebih menyoroti mengenai suasana musim panas yang panjang "lautan api dimusim kemarau” kata penyair bagai tsunami menggulung. Kemudian pada bait berikutnya penyair menggambarkan keadaan rumahnya yang telah tiada " seketika/ rumah kital tiada”. Selanjutnya pada larik berikutnya penyair hanya bisa melihatnya dan menyadari bahwa dia tidak sempat
\end{abstract} bersyukur.

\section{Aspek Kebahasaan dalam Puisi “ Tak Sempat Bersyukur” karya Erfan Heri}

\section{Unsur Fonologis dalam Puisi “ Tak Sempat Bersyukur” karya Erfan Heri}

Berkaitan dengan unsur fonologis, pada puisi “ Tak Sempat Bersyukur” terdapat perbedaan bunyi. Bait pertama diakhir larik pertama, kedua, ketiga terdapat persamaan bunyi vokal $i$ pada kata api dan tsunami, pada larik kedua terdapat bunyi vokal $u$ pada pada kata kemarau, larik keempat terdapat bunyi konsonan $g$ pada kata menggulung, pada larik kelima dan keenam terdapat bunyi konsonan $p$ pada kata melahap dan atap - atap. Pada bait kedua terdapat bunyi konsonan $h$ pada kata langkah, larik kedua dan ketiga terdapat persamaan bunyi vokal a pada kata hara dan sugra. Pada bait ketiga terdapat persamaan bunyi vokal $a$, pada kata seketika, kita, dan tiada. Pada bait 
keempat dilarik pertama terdapat bunyi vokal a diakhir lariknya pada kata seketika, larik kedua,ketiga dan kelima terdapat bunyi konsonan $r$ pada kata tersungkur, sadar, dan bersyukur. Secara keseluruhan dominan dengan bunyi vokal $a$,dominannya bunyi vokal $a$, unsur bunyi yang terasa berat, nampaknya terkait dengan apa yang ingin di kemukakan pada puisi tersebut, terutama mengenai berharganya waktu bagi manusia.

\section{Unsur Leksikal dalam Puisi “ Tak Sempat Bersyukur” karya Erfan Heri}

Sesuai dengan suasana serta pesan yang ingin disampaikan, unsur leksikal pada puisi tersebut dominan kata yang mengandung bunyi vokal $a$. Beberapa kata yang mengandung bunyi vokal $a$, dapat disebutkan misalnya bagai, setiap, atap-atap, langkah, hara, surga, seketika, kita, tiada, sadar, selama, setempat.

\section{Unsur Gramatikal dalam puisi “ Tak Sempat Bersyukur” karya Erfan Heri}

Berkenaan dengan unsur gramatikal, puisi tersebut di tulis larik demi larik, antara larik satu dengan larik berikutnya disusun berurutan secara linier. Ada pula larik yang ditulis tidak berdiri sendiri, melainkan merupakan satu kesatuan. Misalnya bait kedua, pada larik pertama "memecah langkah/huru hara”, kedua larik ini tampaknya merupakan satu kesatuan. Begitu pula pada bait ketiga, pada larik kedua dan ketiga "rumah kita/tiada" Nampak juga merupakan satu kesatuan yaitu pada larik keempat dan kelima "selama ini/tak sempat bersyukur" meskipun demikian, kata demi kata disusun secara gramatikal tidak ada penyimpangan struktur.

\section{Puisi “ Panorama Alam” karya Ida Eliyanti Rahman}

\section{Panorama Alam}

Nyanyian alam mendayu-dayu

Riak air menari-nari

Melambai-lambai daun menari

Menyambut fajar yang dinanti

Kicau burung mengalun syahdu

Membawa jiwa melayang

Tak henti-henti

Seakan berlomba-lomba meraih mimpi

Gunung-gunung gagah berdiri

Dikeliling hujaunya permadani

Titik embun yang berkilau

Menyambut datangnya pagi

Puisi di atas memberikan gambaran mengenai keindahan alam. Penyair memulai puisinya dengan ungkapan “ nyanyian alam mendayu-dayu” kemudian dilanjutkan dengan pernyataan “ riak air menari-nari”. Sehubungan dengan pemandangan alam yang dilihatnya, dedaunan bergoyangan 
menyambut cerahnya hari “ melambai-lambai daun menari/ menyambut fajar yang dinanti”. Dapat diketahui gambaran panorama alam pada pagi hari.

Bait kedua, penyair kembali menggambarkan keindahan alam dengan terdengarnya " kicau burung mengalun syahdu/ membaawa jiwa melayang/ tak henti-hentil seakan berlomba meraih mimp” $i$. Pada bait ketiga, penyair kembali menggambarkan keadaan disekelilingnya " gununggunung gagah berdiri/ dikelilingi hijaunya permadani”. Masih mengenai suasana pagi kembali mengemukakan keindahan yang disaksikannya " titik-titik embun yang berkilau/ menyambut datangnya pagi”.

\section{Aspek Kebahasaan dalam Puisi “ Panorama Alam” karya Ida Eliyanti Rahman Unsur Fonologis dalam Puisi “ Panorama Alam” karya Ida Eliyanti Rahman}

Berkaitan dengan unsur fonologis, pada puisi “Panorama Alam” ini dominan dengan bunyi vokal $a$ dan $u$. dominannya bunyi vokal $a$ dan $u$, tampaknya terkait tentang apa yang ingin dikemukakan oleh penyair dalam puisi tersebut, terutama mengenai keindahan alam yang disaksikan penyair. Suasana seperti itu tampaknya sangat cocok denga dominannya bunyi vokal $a$ dan $u$ yaitu bunyi yang terasa lembut dan berat.

\section{Unsur Leksikal dalam Puisi “ Panorama Alam” karya Ida Eliyanti Rahman}

Sesuai dengan suasana serta pesan yang ingin disampaikan, unsur leksikal pada puisi tersebut dominan mengandung bunyi vokal $a$ dan $u$. beberapa kata yang mengandung bunyi vokal $a$, dapat disebutkan misalnya nyanyian, alam, riak, air, melambai-lambai, fajar, membawa, gagah,datangnya, dan pagi. Beberapa kata yang mengandung bunyi vokal $u$, dapat disebut misalnya mendayu-dayu, menyambut, kicau, burung, mengalun, syahdu, gunung-gunung hijau, embun, dan berkilau.

\section{Unsur Gramatikal dalam Puisi “ Panorama Alam” karya Ida Eliyanti Rahman}

Berkenaan dengan unsur gramatikal, puisi tersebut ditulis larik demi larik. Antara larik satu dengan yang lainnya disusun berurutan secara linier. Ada juga larik yang ditulis tidak berdiri sendiri, melainkan satu kesatuan. Misalnya pada bait kedua, larik kedua dengan ketiga " membawa jiwa melayang/ tak henti-henti”, kedua larik ini tampaknya satu kesatuan. Meskipun demikian, kata demi kata disusun secara gramatikal. Tidak ada penyimpangan struktur.

\section{SIMPULAN}

Berdasarkan hasil kajian mengenai Aspek Kebahasaan dalam antologi puisi “ Hulu Sungai Tengah dalam Pantun dan Puisi” karya anak-anak Banua, maka dapat disimpulkan Aspek 
kebahasaan dalam antologi puisi ini menggunakan beberapa unsur yaitu: a) fonologis dominan dengan bunyi vokal a ,e, i, dan u b) leksikal terdapat 321 kata yang dominan mengandung bunyi vokal a,e,i, dan u, juga banyak terdapat pengulangan kata, c) gramatikal, disusun secara linier dan tidak ada penyimpangan struktur.

\section{DAFTAR RUJUKAN}

Endraswara, Suwardi. Metodologi Penelitian Sastra. Yogyakarta . CAPS

FarhadthIb, 2013 : Worppress.com ( online) ( diakses 15 Mei 2015)

Hermawan, Sainul. Hulu Sungai Tengah dalam Pantun dan Puisi. Banjarbaru. Scripta Cendikia.

Jamalidin, 2003. Problematik Pembelajaran Sastra. Yogyakarta. Adi Cita Karya Nusa

Malini, Lara. 2014. Kebudayaan Banjar dalam Antologi Puisi Burinik Karya Arsyad Indradi (Perspektif Antropologi Sastra). Skripsi tidak diterbitkan. Banjarmasin: STKIP PGRI Banjarmasin.

Pradopo, 2010. Pengkajian Puisi. Gadjah Mada Universersity Press.

Ratna, Nyoman Kutha, 2011. Teori, Metode, dan Teknik Penelitian Sastra. Yogyakarta Kreasi Wacana'

Saraswati, Ekarini. 2003. Sosiologi Sastra. Malang: UMM Press.

Sulistyowati, Endang. Kajian Puisi (Struktural, Semiotik, Stilistika, Bandingan, dan Sosiologi). Banjarbaru: Scripta Cendikia.

Sulistyowati, Endang, Tarman Effendi Tarsyad,2014. Aneka Kajian Prosa Fiksi. Banjarmasin: Tahura Media.

Tarsyad, Tarman Effendy. 2011. Warna Lokal Banjar dalam Puisi. Banjarmasin: Tahura Media. 